\title{
TURISMO Y PAZ: UNA APUESTA PARA EL DESARROLLO EN LA REGIÓN DE URABÁ-DARIÉN
}

Pedro Alejandro Villamizar Barahona*

\section{Resumen}

La importancia que el turismo ha cobrado a nivel mundial no ha sido ajena a la realidad de Colombia, lo que lo posiciona hoy en día como uno de los sectores claves para la economía nacional. La mejora en las condiciones de seguridad en el Urabá-Darién ha permitido que la región le haya apostado al turismo como medio para alcanzar el desarrollo, por su capacidad de fortalecer la cohesión social, mejorar los imaginarios sociales y generar ingresos. La apropiación que ha hecho la comunidad de esta región del turismo como medio de desarrollo resulta fundamental para que en un contexto de posconflicto el sector le pueda aportar a la construcción y el mantenimiento de escenarios de paz.
Palabras clave: paz, violencia, turismo, desarrollo, Urabá-Darién.

\section{TOURISM AND PEACE: A BET FOR DEVELOPMENT IN URABÁ-DARIÉN}

\begin{abstract}
The importance that tourism has gained worldwide has not been oblivious to the reality of Colombia, positioning it today as one of the key sectors for the national economy. The improvement in security conditions in Urabá-Darién has enabled the region to bet on tourism as a means for achieving development for its ability to strengthen social cohesion, improve social imaginary and generate
\end{abstract}

* Magíster en Gerencia para el Desarrollo, Universidad Externado de Colombia. Encargado de los temas de relaciones internacionales y cooperación en turismo, en el Ministerio de Comercio, Industria y Turismo (Colombia). pedroalejandro84@hotmail.com

Recibido: 21/09/2016/ Modificado: 10/01/2017/ Aceptado: 11/01/2017.

Para citar este artículo

Villamizar Barahona, P. A. (2017). Turismo y paz: una apuesta para el desarrollo en la región de Urabá-Darién. OPERA, 20, pp. 107-127.

DOI: https://doi.org/10.18601/16578651.n20.06 
income. The appropriation that the community of this region has made on tourism as a means of development becomes essential for a post-conflict scenario, due the capacity of this sector to contribute to the construction and maintenance of peace scenarios.

Key words: Peace, violence, tourism, development, Urabá-Darién.

\section{INTRODUCCIÓN}

La Organización Mundial del Turismo (омт) (2015) considera que el turismo se ha convertido en un sector clave para el desarrollo, la prosperidad y el bienestar, debido a su gran potencial para el progreso socioeconómico, representado por la creación de puestos de trabajo y empresas, la construcción de infraestructura y la generación de ingresos.

El turismo ha demostrado ser un importante factor de desarrollo que genera territorios de paz, [...] en tanto se le considera como uno de los sectores que genera mayor redistribución de los ingresos y genera más trabajos con menos capital invertido [...]. En ese orden de ideas, el turismo está llamado a continuar jugando un importante papel en el desarrollo social y económico, en el marco de la visión trazada por el Gobierno nacional a 2025: Colombia en paz, con equidad y educada (Ministerio de Comercio, Industria y Turismo, Viceministerio de Turismo, Departamento Nacional de Planeación, 2014, p. 6).

En Colombia, el sector turismo se ha convertido en uno de los más importantes sectores para el desarrollo del país, de tal suerte que este se ha posicionado como tercer gene- rador de divisas, justo detrás del petróleo y del carbón (Lacouture, 2016). Según un informe presentado por el Ministerio de Comercio, Industria y Turismo (Minciт) en febrero de 2016, Colombia recibió en el 2015 un total de 5.251 millones de dólares en divisas por concepto de turismo, consecuente con la creciente llegada de turistas al país, que contabilizó, para ese año, un total de 4.447.004 viajeros extranjeros.

En este sentido, el Gobierno nacional se ha propuesto como meta para el 2018, en el área del turismo, incrementar el ingreso de divisas a 6.000 millones de dólares y aportar a la economía 300.000 nuevos empleos, cifra que supera los 235.000 generados durante el periodo 2011-2014 (El Tiempo, 2015).

Si bien el panorama del turismo en Colombia es positivo, no es posible analizar la evolución y el desarrollo del sector sin tener en cuenta la dinámica del conflicto armado. Este se ha extendido por más de 50 años y se ha caracterizado por la lucha contra grupos guerrilleros, grupos paramilitares y el narcotráfico. Así lo evidencia el informe presentado por la Comisión Histórica del Conflicto y sus Víctimas (CHCV) (2015) a la mesa de conversaciones de La Habana en febrero de 2015, en donde se denota la magnitud de la violencia en el país, y se resaltan los efectos adversos de la presencia de estos grupos al margen de la ley y vinculados al negocio del narcotráfico. Esta dinámica de violencia en Colombia ha sido, sin duda, uno de los factores que más ha impactado negativamente en el turismo. Debe entenderse que la seguridad es un prerrequisito para que el turista decida visitar un territorio, pero la incidencia de actos violentos 
en el país ha impedido que regiones con gran potencial para alcanzar un mayor desarrollo económico y social mediante el turismo se hayan podido insertar en la cadena productiva del sector.

Ahora bien, el turismo es una actividad en la que deben confluir diferentes tipos de prestadores de servicios y proveedores de bienes, tales como establecimientos de alojamiento y hospedaje, de gastronomía y bares, guías turísticos, agencias de viajes, entre otros. Gracias a lo anterior, el desarrollo de esta actividad se puede convertir en una oportunidad para afianzar la cohesión social en las comunidades receptoras, de manera que el turismo pueda servir de herramienta constructora de paz, consolidando escenarios de paz en territorios con historial de violencia.

No obstante, aunque el turismo cuenta con el potencial para convertirse en un sector motor del desarrollo en una región, también puede generar tensiones que se traduzcan en una reactivación del conflicto o en un incremento de los niveles de violencia. En este sentido, hay que tener en cuenta efectos negativos como el uso inadecuado de los recursos naturales, el incremento y manejo inadecuado de las basuras, la exclusión de la población local de los beneficios económicos derivados del desarrollo de la actividad turística, la estacionalidad en la generación de empleos, el aumento de precios (Aguilera, Bernal y Quintero, 2006), así como fenómenos como la explotación comercial sexual de niños y nińas, entre otros.

Por tal motivo, este artículo buscará responder si el turismo puede aportar a la construcción de escenarios de paz, convivencia y desarrollo centrándose, concretamente, en la región Urabá-Darién.

Frente a ese interrogante, se parte de la siguiente hipótesis: en la región de UrabáDarién, el turismo tiene la capacidad para fortalecer la cohesión social, mejorar los imaginarios sociales de las personas afectadas por la presencia de grupos alzados en armas en su territorio y ayudar a la generación de ingresos de la población local. Estos factores hacen parte del proceso de construcción de paz, convivencia y desarrollo económico y social en la región.

El análisis que se plantea en este trabajo tiene una estrecha relación con la estrategia "Turismo, paz y convivencia” que adelanta la máxima autoridad del turismo en el país, el Ministerio de Comercio, Industria y Turismo. Dicha iniciativa pretende preparar a las comunidades locales de territorios históricamente afectados por el conflicto armado interno, para aprovechar el turismo como herramienta no solo de un desarrollo económico y social, sino como medio para convertir escenarios de guerra en territorios de paz.

Como parte de ese plan, el Ministerio definió cuatro regiones piloto para adelantar un trabajo que permita la consolidación de escenarios de paz en torno al desarrollo del turismo, en territorios con historial de violencia. Estas cuatro regiones piloto son el camino Teyuna, en la Sierra Nevada de Santa Marta, La Macarena, el departamento del Putumayo y la región del Urabá-Darién.

Regiones como La Macarena o el UrabáDarién presentan los mejores avances en la implementación de estrategias de desarrollo local en torno al turismo. Por ende, esta últi- 
ma región será utilizada como caso de estudio para determinar la posibilidad real que tiene el turismo de aportar al desarrollo y a la consolidación de escenarios de paz y convivencia en el territorio colombiano. Importantes son los avances que allí se han logrado, de la mano de organizaciones internacionales, empresas privadas y los gobiernos nacional y local, los cuales serán abordados más adelante.

En un posible escenario de posconflicto ${ }^{1}$ que se avecina en Colombia, el turismo puede afianzarse como una alternativa de generación de ingresos, cohesión social y desarrollo para las comunidades que, históricamente, han sido víctimas o victimarios dentro del conflicto armado colombiano en las diferentes regiones del país. La mejora en las condiciones de seguridad en territorios colombianos con alto potencial turístico - alcanzadas una vez se haya superado el conflicto-, permitirá que el sector pueda dinamizarse y aportar aún más al desarrollo de estas regiones y de sus pobladores (Gómez, 2002).

Si se considera que el turismo es una de las actividades económicas que socialmente tiene la capacidad de generar un desarrollo sostenible, mediante la inclusión social y la reducción de la pobreza (Yunis, 2011), resulta de vital importancia identificar aquellas condiciones necesarias para que el sector pueda aportar, en mayor medida, a la consolidación de escenarios de paz y convivencia. Esto es fundamental, ya que una correcta imple- mentación de esos proyectos turísticos y el involucramiento activo de las comunidades locales podrían afectar positivamente el mantenimiento de la paz y la seguridad. Claro está que, en caso contrario, esos objetivos podrían verse amenazados e, incluso, irían en detrimento de la anhelada construcción de paz.

A la luz de este panorama, el objetivo principal del presente artículo es determinar los elementos que le permiten al turismo convertirse no solo en una herramienta para alcanzar el desarrollo económico y social, sino también en un vehículo para construir y afianzar territorios de paz.

Este documento se divide en cuatro partes: en la primera se describirá el panorama del turismo a nivel internacional y nacional; en la segunda, se hará una reflexión teórica sobre el conflicto y la paz en general, y la relación entre turismo y paz; la tercera parte abordará la experiencia de la región del Urabá-Darién, como zona afectada por el conflicto armado interno colombiano, pero con un gran potencial para el desarrollo y la consolidación de la paz mediante el turismo; la última sección se centrará en presentar, a manera de conclusión, los resultados del análisis sobre los factores que permiten que el turismo pueda aportar a la construcción de escenarios de paz, convivencia y desarrollo en la región del Urabá-Darién.

1 Se entiende como posible escenario de posconflicto aquel contexto del país posterior a la firma de los acuerdos de paz con la guerrilla de las Fuerzas Armadas Revolucionarias de Colombia - Ejército del Pueblo (FARC-EP). 


\section{IMPORTANCIA DEL SECTOR TURISMO}

Los datos presentados por el organismo especializado de las Naciones Unidas para el turismo dan cuenta de la importancia que este sector ha cobrado para el desarrollo económico y social de la población mundial. El turismo no solamente está haciendo importantes aportes en términos del producto interno bruto (РIв) a nivel mundial, sino que también es responsable de la creación de un gran número de empleos (омт, 2015).

Según datos de la misma organización (2015), el turismo representa el $9 \%$ del PIB mundial, genera uno de cada once empleos en el mundo, y constituye el $30 \%$ de las exportaciones de servicios. Hoy en día, iguala o supera las exportaciones de sectores como el de los alimentos, el petróleo o los automóviles; en el 2014 representó el $6 \%$ de las exportaciones mundiales, lo que equivale a 1,5 billones de dólares en exportaciones, y ha pasado de 25 millones de turistas internacionales en 1950 a 1.133 millones en 2014 .

La facilitación de los viajes sin duda ha sido uno de los factores cruciales para el creciente desarrollo del turismo mundial, y así lo reconocieron los representantes de Gobierno y sector privado colombiano asistentes a la XXI Asamblea General de la omT realizada en Medellín en septiembre del 2015:

La facilitación, cuando sea factible, de las formalidades y procedimientos de viaje con respecto a los puntos de entrada y salida, las aduanas, las divisas, la seguridad y la protección, así como las, regulaciones sanitarias, resulta crucial para que los sectores del turismo y del transporte aéreo mantengan su resiliente crecimiento y saquen fruto de su potencial de desarrollo (Organización de las Naciones Unidas, 2015, p. 4).

En términos de diversificación de destinos (tabla 1), históricamente Europa ha sido la región del mundo que ha registrado el mayor número de turistas internacionales desde 1990, con una participación en el mercado del 51,4\% para 2014. No obstante, la tendencia en regiones como Asia-Pacífico o las Américas muestra un crecimiento promedio anual del 6,1 y 3,5\% respectivamente, mayor que el promedio para Europa, que registra un crecimiento del 3,5\%.

Para el turismo en Colombia, esta realidad no ha sido ajena y, por el contrario, los datos parecen ser aún más alentadores. Si bien el promedio de crecimiento del turismo reportado por la omT para el año 2015 fue del $4,4 \%$, en Colombia, de enero a octubre de ese mismo año, se ubicó en un 9\% (Revista Dinero, 2016).

En este sentido cabe destacar que, para diciembre de 2015, la llegada a Colombia de turistas de países como Estados Unidos creció un 27,0\%; de México, un 31,7\%, y de Panamá, un 34,5\%, en comparación con el mismo periodo de 2014 (Ministerio de Comerico, Industria y Turismo, 2015). El informe también señala que, aunque en términos regionales, en el interior del país Bogotá es la ciudad con mayor participación en la recepción de extranjeros no residentes, en el mes de diciembre de 2015 otras regiones -como Antioquia, Risaralda o Valle del Cauca- fueron las que reportaron un mayor crecimiento en relación con el mismo periodo de 2014. 
TABLA 1. LLEGADA DE TURISTAS INTERNACIONALES POR REGIONES

\begin{tabular}{|c|c|c|c|c|c|c|c|c|c|c|c|c|}
\hline & \multicolumn{7}{|c|}{$\begin{array}{l}\text { Llegada de turistas internacionales } \\
\qquad \text { (millones) }\end{array}$} & \multirow{2}{*}{$\begin{array}{c}\text { Cuota de } \\
\text { mercado } \\
(\%)\end{array}$} & \multicolumn{3}{|c|}{ Variación (\%) } & \multirow{2}{*}{$\begin{array}{c}\begin{array}{c}\text { Crecimien- } \\
\text { to medio } \\
\text { anual (\%) }\end{array} \\
05-14\end{array}$} \\
\hline & 1990 & 1995 & 2000 & 2005 & 2010 & 2013 & 2014 & & $12 / 11$ & $13 / 12$ & $14 / 13$ & \\
\hline Mundo & 435 & 527 & 674 & 809 & 949 & 1,087 & 1,133 & 100 & 4,2 & 4,6 & 4,3 & 3,8 \\
\hline $\begin{array}{l}\text { Economías } \\
\text { avanzadas }\end{array}$ & 296 & 336 & 420 & 466 & 513 & 586 & 619 & 54,7 & 4,0 & 4,7 & 5,8 & 3,2 \\
\hline $\begin{array}{l}\text { Economías } \\
\text { emergentes }\end{array}$ & 139 & 191 & 253 & 343 & 435 & 501 & 513 & 45,3 & 4,4 & 4,5 & 2,4 & 4,6 \\
\hline \multicolumn{13}{|l|}{$\begin{array}{l}\text { Por regiones de la } \\
\text { OMT: }\end{array}$} \\
\hline Europa & 261,5 & 304,7 & 386,4 & 453,0 & 488,9 & 566,4 & 581,8 & 51,4 & 3,9 & 4,9 & 2,7 & 2,8 \\
\hline Europa del Norte & 28,7 & 36,4 & 44,8 & 59,9 & 62,8 & 67,4 & 71,3 & 6,3 & 1,5 & 2,9 & 5,9 & 2,0 \\
\hline Europa Occidental & 108,6 & 112,2 & 139,7 & 141,7 & 154,4 & 170,8 & 174,5 & 15,4 & 3,6 & 2,8 & 2,2 & 2,3 \\
\hline $\begin{array}{l}\text { Europa Central/ } \\
\text { Oriental }\end{array}$ & 33,9 & 58,1 & 69,3 & 95,1 & 98,4 & 127,3 & 121,1 & 10,7 & 9,1 & 7,7 & $-4,9$ & 2,7 \\
\hline $\begin{array}{l}\text { Europa Meridional/ } \\
\text { Medit. }\end{array}$ & 90,3 & 98,0 & 132,6 & 156,4 & 173,3 & 201,0 & 214,9 & 19,0 & 1,9 & 5,6 & 6,9 & 3,6 \\
\hline de los cuales UE-28 & 230,1 & 268,0 & 330,5 & 367,9 & 384,3 & 433,8 & 455,1 & 40,2 & 3,0 & 4,0 & 4,9 & 2,4 \\
\hline Asia y el Pacífico & 55,8 & 82,1 & 110,3 & 154,0 & 205,4 & 249,8 & 263,3 & 23,2 & 6,9 & 6,8 & 5,4 & 6,1 \\
\hline Asia del Nordeste & 26,4 & 41,3 & 58,3 & 85,9 & 111,5 & 127,0 & 136,3 & 12,0 & 6,0 & 3,4 & 7,3 & 5,3 \\
\hline Asia del Sudeste & 21,2 & 28,5 & 36,3 & 49,0 & 70,5 & 94,3 & 96,7 & 8,5 & 8,7 & 11,3 & 2,6 & 7,9 \\
\hline Oceanía & 5,2 & 8,1 & 9,6 & 10,9 & 11,4 & 12,5 & 13,2 & 1,2 & 4,2 & 4,6 & 5,7 & 2,1 \\
\hline Asia Meridional & 3,1 & 4,2 & 6,1 & 8,1 & 12,0 & 16,0 & 17,1 & 1,5 & 5,9 & 11,4 & 6,8 & 8,6 \\
\hline Américas & 92,8 & 109,1 & 128,2 & 133,3 & 150,1 & 167,5 & 181,0 & 16,0 & 4,5 & 3,1 & 8,0 & 3,5 \\
\hline América del Norte & 71,8 & 80,7 & 91,5 & 89,9 & 99,5 & 110,2 & 120,4 & 10,6 & 4,1 & 3,6 & 9,2 & 3,3 \\
\hline El Caribe & 11,4 & 14,0 & 17,1 & 18,8 & 19,5 & 21,1 & 22,4 & 2,0 & 3,1 & 2,8 & 6,2 & 2,0 \\
\hline América Central & 1,9 & 2,6 & 4,3 & 6,3 & 7,9 & 9,1 & 9,6 & 0,8 & 7,3 & 2,6 & 5,6 & 4,8 \\
\hline América del Sur & 7,7 & 11,7 & 15,3 & 18,3 & 23,1 & 27,1 & 28,6 & 2,5 & 6,3 & 1,5 & 5,4 & 5,1 \\
\hline África & 14,7 & 18,7 & 26,2 & 34,8 & 49,5 & 54,4 & 55,7 & 4,9 & 4,8 & 4,7 & 2,4 & 5,4 \\
\hline África del Norte & 8,4 & 7,3 & 10,2 & 13,9 & 18,8 & 19,6 & 19,8 & 1,7 & 8,7 & 6,0 & 0,9 & 4,0 \\
\hline África Subsahariana & 6,3 & 11,5 & 16,0 & 20,9 & 30,8 & 34,7 & 35,9 & 3,2 & 2,8 & 4,1 & 3,3 & 6,2 \\
\hline Oriente Medio & 9,6 & 12,7 & 22,4 & 33,7 & 54,7 & 48,4 & 51,0 & 4,5 & $-5,3$ & $-3,1$ & 5,4 & 4,7 \\
\hline
\end{tabular}

Fuente: OMT (2015). 
Estas cifras podrían dar visos del potencial que tiene el país para el desarrollo del turismo en otras regiones de Colombia. Si se tiene en cuenta que la región de mayor crecimiento fue Antioquia, podría vislumbrarse una gran oportunidad para el desarrollo del turismo en regiones como la del Urabá-Darién.

Este rápido panorama del turismo a nivel mundial y en Colombia deja ver la importancia que tiene hoy en día el sector, no solamente en términos de generación de ingresos, sino también de impacto social. En este sentido, el diseño y la correcta implementación de políticas públicas y programas que permitan dinamizar el turismo debe ser una prioridad para el progreso de regiones con gran potencial de desarrollo turístico, especialmente aquellas que se ven limitadas por un fuerte historial de violencia.

De la misma manera, hay que tener presente que para el desarrollo de proyectos turísticos sostenibles en territorios con historial de violencia, no solamente bastarán políticas básicas de desarrollo productivo y apoyo a las regiones, sino que se deberán tener en cuenta procesos novedosos de inclusión de personas que son consideradas como victimarios pero que se incorporarán a la vida civil.

\section{CONFLICTO, PAZ Y TURISMO, UNA REFERENCIA TEÓRICA}

Para examinar la relación existente entre conflicto, turismo y paz, hay que detenerse a examinar cuáles son los aspectos desencadenantes de violencia en las relaciones humanas. De la misma manera, debe retomarse el con- cepto de paz, para poder entender cómo es posible alcanzarla y mantenerla dentro de una sociedad, como un prerrequisito de desarrollo.

Para hacer una reflexión teórica sobre el origen de la violencia se puede acudir a conceptos como el "triángulo de la violencia" acuñado por Johan Galtung. Ese triángulo está compuesto por la violencia directa, la violencia estructural y la violencia cultural. La última puede ser entendida como insatisfacciones en aspectos relacionados con la existencia misma del hombre, tales como la religión, la ideología, el lenguaje y el arte, entre otras, que legitiman posteriormente, de una u otra manera, la violencia directa o la estructural (Galtung, 1990). Como explica el autor, la violencia, para el ser humano, se ve justificada por una necesidad de satisfacción de necesidades internas sobre los aspectos de la existencia mencionados, y que pasa por necesidades en términos de sobrevivencia, identidad, libertad o bienestar.

Así las cosas, la violencia cultural puede interpretarse como aquel tipo de violencia que legitima comportamientos o actitudes violentas de un ser humano hacia su entorno. De la misma manera, esa violencia genera un marco de aceptación por parte del que la sufre, ya que ve justificado el actuar violento de un individuo, basado en convicciones tan fuertes como la ideología o la religión (Galtung, 1990).

En la parte superior de este triángulo se encuentra la violencia directa, que es la más visible y fácilmente identificable, porque es la que se materializa directamente por el hombre (Galtung, 1990). En este tipo de violencia hay un ataque directo, ya sea físico, verbal o psicológico (Calderón, 2009). 
En la otra punta del triángulo se encuentra la violencia estructural, en la cual las estructuras sociales, políticas o económicas insertas en los Estados (Calderón, 2009) impiden el gozo pleno de las necesidades individuales y generan fenómenos tales como la segmentación, segregación o fragmentación de la sociedad (Galtung, 1990).

Según este enfoque, el mantenimiento de un escenario de conflicto en una sociedad se explicaría por la permanencia de un comportamiento violento arraigado en la misma cultura, y que se ve justificado por la frustración del hombre en poder cumplir de manera pacífica con las necesidades que son básicas para su interacción con los demás y con su entorno.

Sin embargo, no solamente los factores culturales o estructurales podrían determinar los niveles de violencia en un territorio, sino que se puede también retomar a Stathis Kalyvas, quien postula que el grado de violencia está determinado por el nivel de control que un actor armado ejerce sobre un territorio; mientras más control tenga un grupo sobre la región, los habitantes serán más propensos a colaborar y a denunciar, lo que incidiría en una disminución de los niveles de violencia (Rožič, 2008).

En este mismo sentido, si el actor armado es consciente de esta colaboración, sus acciones no se orientarán hacia un escalamiento de la violencia hacia la población, sino que, por el contrario, se podrán construir escenarios de colaboración conjunta, en los cuales se logre una disminución de la misma.

Si se entiende que lo totalmente opuesto a la violencia es la paz, se podría, al menos de manera teórica, entender cuáles son los mo- tivos desencadenantes de la violencia, de tal suerte que se pudiera llegar a un escenario de paz que pudiera ser mantenido en el tiempo.

Ahora bien, visto desde el punto de vista de la paz y no del conflicto, se podría acudir a conceptos como "la paz negativa" y "la paz positiva”, explicados por el mismo Galtung. Por un lado, la paz negativa podría considerarse como aquella en la cual hay una ausencia de violencia directa (Jiménez, 2009). En este sentido, el autor argumenta que la ausencia de violencia directa solo debe ser entendida como paz negativa, ya que las insatisfacciones de una sociedad pueden estar presentes, pero no se han manifestado, por lo que no se podría hablar de un escenario de paz total.

Por el otro lado, se encuentra el concepto de paz positiva, en la cual no se presenta una violencia estructural o indirecta debido a que la sociedad en sí misma tolera las desigualdades sociales, económicas o políticas (Jiménez, 2009).

Dentro de otros avances teóricos para explicar el concepto de paz se debe retomar el término de "paz neutra", en la cual hay una ausencia total de la violencia cultural (Jiménez, 2009). Según la concepción del autor, la paz total absoluta no existe, sino que debe coexistir con el conflicto, así que el diálogo y la capacidad del ser humano de querer vivir en un escenario de paz deben ser suficientes para poder neutralizar un intento de predominio de violencia cultural en las relaciones humanas, de tal suerte que se pueda alcanzar una paz neutra.

En este sentido, se podría entender que la paz no es necesariamente una condición en la cual no existan razones que pudieran ser 
desencadenantes de violencia, sino que, por el contrario, pueden existir, pero la sociedad decide esforzarse por alcanzar y mantener un escenario de paz.

Si bien, como lo anota Galtung, hay factores de insatisfacción por parte del ser humano que son desencadenantes de la violencia y del conflicto, conceptos como la paz neutra, en la que no hay una manifestación de violencia directa como una guerra, o en la que hay una ausencia total de violencia cultural, hacen pensar que sí es posible el mantenimiento de un escenario de paz parcial, tal vez con algún grado de insatisfacción de las necesidades, pero, al mismo tiempo, con un grado de aceptación de una realidad social.

Entendidos los conceptos de paz y los tipos de violencia, se podría desear que la paz positiva sea el objetivo final dentro de cualquier tipo de relación social, ya que allí habría una ausencia total de cualquier tipo de violencia. Sin embargo, hay que tener presente la estructura política y económica que se vive en el mundo, en donde se hace imposible pensar en una satisfacción total de las necesidades de todos y cada uno de los integrantes de una sociedad.

Así las cosas, acudiendo a la capacidad que tiene el hombre para utilizar el diálogo como medio de solución de sus problemas y a su deseo de vivir en un escenario de paz, podría pensarse que, bajo una óptica teórica, la reducción de los niveles de violencia se podría alcanzar teniendo como objetivo la búsqueda de, por lo menos, una paz neutra.

Ahora, vistos los conceptos de violencia y paz, es necesario hacer una revisión teórica acerca de la construcción de paz. Esta debe ir más allá de la resolución de conflictos mediante negociaciones de paz o triunfos militares, ya que no involucra de manera exclusiva a los actores armados que participan del conflicto; por el contrario, hacen parte actores como la Iglesia, la sociedad civil y la comunidad internacional, entre otros. Su proceso empieza mucho antes y tiene un horizonte de tiempo que va más allá de lo que puede durar un proceso de paz (Rettberg, 2013).

De igual forma, como lo plantea Angelika Rettberg (2013), hay que tener presentes aportes como el de la pertenencia local, el cual habla de la necesidad de la apropiación local que debe hacer un país o una comunidad en torno a la construcción de escenarios de paz. Es imperativo entender, en este punto, que la paz no puede ser implantada en un territorio por un foráneo, sino que, por el contrario, su construcción debe estar en manos de sus mismos habitantes, para generar un alto grado de pertenencia y legitimidad en los procesos.

Esta revisión de conceptos sobre los orígenes y los tipos de violencia, los diferentes conceptos de paz y la manera de construirla, permite empezar a tejer una relación entre cómo uno de los sectores más dinamizadores de la economía mundial -el turismo-, puede aportar a la construcción de escenarios de paz y al desarrollo económico y social de una sociedad. Si bien el turismo no está dirigido a acabar con los brotes de violencia directa, sí podría llegar a incidir positivamente en la reducción de los niveles de violencia estructural y cultural, es decir, en la consecución de algún grado de paz, bien sea positiva o neutra.

La contribución del turismo en favor de la paz se reconoció hace ya casi cincuenta 
años cuando, en 1967, la Organización de las Naciones Unidas proclamó el Año Internacional del Turismo, bajo el lema "Turismo pasaporte para la paz" (омт, 2015). Este tipo de declaraciones buscaba enfocar las miradas del mundo hacia el sector para que diversos actores, tanto públicos como privados, comprendieran la importancia del turismo como factor clave del desarrollo económico y social $y$, en este caso específico, como una herramienta con un gran potencial para alcanzar la paz.

En este sentido, es muy valioso el trabajo realizado por Wohlmuther y Wintersteiner (2014), en donde se logra obtener la percepción de actores claves a nivel mundial en las áreas de turismo y paz. Como resultado de ese estudio se obtuvo un compilado de varios artículos que contienen las opiniones de diversos expertos, basadas tanto en teorías académicas como en casos prácticos, en torno a temáticas como el desarrollo, la democracia, la resolución de conflictos y la paz, todos ellos relacionados con la dinámica propia del sector turismo.

Wohlmuther y Wintersteiner (2014) sostienen que el turismo tiene un gran potencial económico, visto desde la oportunidad de creación de empleo e ingresos, la cual puede generar un empoderamiento de la población que redunde en una reducción de la violencia y el conflicto. Sin embargo, también argumentan que el mayor beneficio del turismo a la construcción de paz no es el componente económico, sino que debe con- siderarse la cultura como el principal aporte, ya que mediante el turismo es posible tener un mejor entendimiento del otro, ayudando en la construcción de una cultura de paz y en la prevención del conflicto ${ }^{2}$.

$\mathrm{Si}$ se tienen presentes las desigualdades y los desentendimientos que pueden existir en una sociedad, el desarrollo de una actividad productiva en torno al turismo, que beneficie a todos los integrantes de una sociedad, puede generar espacios de diálogo que permitan comprender las necesidades insatisfechas de la población de tal suerte que se logre llegar a un escenario de paz neutra.

Es imposible pensar que un servicio turístico se preste sin la participación de quien provea el alojamiento, el servicio de restaurante o los insumos para preparar los alimentos, o sin un guía turístico, solo por mencionar algunos de los prestadores de servicios turísticos.

Así las cosas, el concepto de cadena de valor que está de manera implícita dentro del desarrollo de una actividad turística se puede entender como "el conjunto interrelacionado de actividades creadoras de valor, que abarca desde la obtención de fuentes de materias primas hasta que el producto o servicio terminado es entregado al consumidor final" (Moreno y Ochoa, 2011, p. 199).

Moreno y Ochoa (2011) también resaltan que el desarrollo humano no es una búsqueda del bienestar individual, sino que es una construcción colectiva que consiste en comprender las necesidades y los intereses del otro, para

2 Se entiende por cultura de paz y prevención del conflicto, todo actuar individual que permita una convivencia pacífica en sociedad y una resolución no violenta de los problemas. 
permitir llegar a un escenario en que se tomen decisiones colectivas que favorezcan a toda la comunidad y mejoren su calidad de vida.

Es por esta razón que debe considerarse el desarrollo gestionado desde las mismas comunidades como una prioridad para el emprendimiento de proyectos en regiones como la del Urabá-Darién, ya que el entendimiento de los intereses del otro y la toma de decisiones conjuntas alrededor de la implementación de un proyecto turístico podría ayudar a construir escenarios de confianza y bienestar común que, en últimas, redunden en la consolidación de escenarios de paz.

Vale la pena también mencionar que el turismo es una industria transversal que genera impactos en diversos sectores, ya que allí confluyen actividades como la pesca, la agricultura, las artesanías y el transporte. Eso, sin duda, genera un escenario para la inclusión social de las comunidades receptoras de turistas (Yunis, 2011). De igual forma:

Por la amplitud de los servicios que exige para su realización, el turismo es un factor creador de un número considerable de nuevas actividades, fuente de creación de empleos. En tal sentido, constituye un positivo elemento de progreso social en todos los países donde se practica, cualquiera que sea, por otra parte, el grado de desarrollo de esos países (омт, 1980, p. 3).

Así las cosas, se podría vislumbrar un panorama en el que, aun existiendo un cierto grado de violencia o conflicto en una región, se puedan ver desarrollos en torno a la prestación de un servicio turístico que redunden, en últimas, en beneficios económicos y sociales para la población local. Al parecer, este sería el caso de la región del Urabá-Darién, ya que pese a su evidente historial de violencia, parece apostarle al desarrollo del turismo como alternativa de desarrollo local.

\section{URABÁ-DARIÉN: UNA OPORTUNIDAD PARA EL DESARROLLO ALREDEDOR DEL TURISMO}

Por su ubicación geográfica estratégica, que incluye terreno selvático y la salida al mar Caribe, esta región ha sido propicia para que se hayan desarrollado actividades ilícitas como el tráfico de drogas y de armas, lo que ha motivado, consecuentemente, a lo largo de la historia reciente de Colombia, la localización en esta zona de grupos guerrilleros, paramilitares y bandas criminales (Naranjo, 2014). Allí se han ubicado el Frente 57 de las Fuerzas Armadas Revolucionarias de Colombia - Ejército del Pueblo (FARC-EP) y su compañía móvil, y el bloque Elmer Cárdenas de las Autodefensas Unidas de Colombia (AUC) (Observatorio del Programa Presidencial de Derechos Humanos y Derecho Internacional Humanitario, 2003), así como los grupos armados organizados Rastrojos, Urabeños y Clan Úsuga (Unidad para la Atención y la Reparación Integral de las Víctimas, 2015; Verdad Abierta, 2011).

Datos recogidos por la Consejería Presidencial para los Derechos Humanos (2006) se refieren a masacres como la perpetrada en $\mathrm{La}$ Chinita, en 1994, donde las FARC-EP asesinaron a 35 personas que vivían en este barrio de Apartadó; o como la del municipio de Necoclí, con un saldo de 122 personas desaparecidas y 130 muertas en 1995. Este mismo informe 
alude a las constantes confrontaciones entre las AUC y las FARC-EP entre los años 2000 y 2004 en Mutatá, y del alto número de desplazados que se presentó en los municipios del Urabá antioqueño con posterioridad a la desmovilización del bloque Bananero de las autodefensas en el 2004.

Según datos del Programa de las Naciones Unidas para la Droga y el Delito (UNODC, por sus siglas en inglés), aunque los municipios del medio y bajo Chocó son los que en el periodo 2003-2011 han concentrado la mayor cantidad de cultivos de coca, para el 2011 hubo una expansión de estos hacia el municipio de Acandí en la región del Urabá-Darién, con seis hectáreas detectadas de siembra de coca (UNODC, 2012).

No obstante este panorama violento, el gran potencial para el desarrollo del turismo en la región ha hecho que destinos como Capurganá o Sapzurro siempre hayan estado en la mente de los turistas. En este sentido hay que resaltar datos como la llegada de viajeros extranjeros no residentes en Colombia al municipio de Acandí, la cual pasó de 355 en 2010 a 2.161 en $2015^{3}$ (Migración Colombia, 2016).

Adicionalmente, se puede acudir a información de la alcaldía de este municipio, que destaca el turismo como principal actividad económica de Acandí (Alcaldía de AcandíChocó, 2016); la presencia de estos dos co- rregimientos dentro de las guías turísticas presentadas por ProColombia (2016) en su portal web, como oferta exportable en servicios turísticos; la inversión que se realizará por un valor de 2.976.124.317 millones de pesos (Fondo Nacional de Turismo, 2015), para la construcción del sendero ecoturístico Capurganá-Sapzurro-La Miel, por iniciativa del Mincit; la priorización que ha hecho el Gobierno nacional para la pavimentación de la pista del aeropuerto de Capurganá, por un valor de 2.779 millones de pesos ( $E l$ Tiempo, 2016); o los 32 establecimientos de alojamiento y hospedaje, y las dos agencias de viaje que se encontraban activas a marzo de 2016 en el Registro Nacional de Turismo en el municipio de Acandí (Cámara de Comercio de Bogotá, 2016).

A esto se suma que los niveles de seguridad en la región del Urabá-Darién han mejorado. Así lo demuestra la reducción de los homicidios, que pasaron de 1.000 en el 2005, a 118 casos hasta septiembre de 2014 (El Colombiano, 2015), y la disminución del hurto a personas en los municipios de Acandí y Necoclí ${ }^{4}$, los cuales pasaron de 23 casos en el 2010 a 15 en el 2015 (Ministerio de Defensa, Policía Nacional, Dirección de Investación Criminal e Interpol, s.f.).

Estos datos muestran que la violencia directa ha disminuido en la región, lo que hace pensar que se está logrando la construcción de

\footnotetext{
Cálculos propios, hechos sobre bases de datos de Migración Colombia, utilizados como documentos de trabajo interno dentro del Ministerio de Comercio, Industria y Turismo.

4 Cálculos propios, hechos sobre las bases de datos del Sistema de Información, Estadístico, Delincuencial, Contravencional y Operativo de la Policía Nacional de Colombia.
} 
una paz negativa. Se esperaría, entonces, que la consolidación del turismo como agente de desarrollo en la región del Urabá-Darién logre una mayor cohesión social entre sus habitantes y una mejora de los imaginarios sociales que permitan la construcción de una paz neutra o una paz positiva.

En este punto cabe resaltar que el UrabáDarién tiene un gran potencial para el desarrollo turístico, debido a sus características geográficas únicas, ya que no solamente puede apostarle al turismo de sol y playa, sino que, también, puede aprovechar el ecosistema que lo circunda, para el desarrollo del turismo de naturaleza ${ }^{5}$, considerado como uno de los de más alto valor.

Debido a la oportunidad para lograr un desarrollo rural sostenible a través del turismo en zonas con un historial de violencia y conflicto, el Gobierno nacional, mediante el Ministerio de Comercio, Industria y Turismo, decidió, en el 2014, lanzar la estrategia "Turismo, paz y convivencia”, empezando con cuatro regiones piloto: 1) camino a Teyuna (Ciudad Perdida de la Sierra Nevada de Santa Marta), 2) sierra de La Macarena, 3) Putumayo y 4) Urabá-Darién.

Las regiones piloto fueron formalizadas por el Mincit a través de la "Declaración de Bogotá de paz a través del turismo", adoptada el 27 de junio de 2014 en el marco del XII
Seminario Internacional de la omT. Fueron definidas por criterios como los siguientes: ser sitios que estuvieran incluidos dentro de la estrategia de experiencias únicas ${ }^{6}$, que las autoridades locales tuvieran un compromiso con el desarrollo del turismo y ser territorios con historial de violencia.

La estrategia de "Turismo, paz y convivencia”, para los destinos piloto priorizados por el Mincit, dentro de los cuales se encuentra la región del Urabá-Darién, se viene construyendo desde y con los territorios, respetando sus condiciones únicas, para lograr construir una paz basada en el fortalecimiento del tejido social, mediante el desarrollo del turismo como un actividad económica alternativa.

De esta manera, el 4 y 5 de septiembre de 2014 se instaló en la posada turística El Carlos, en el municipio de Necoclí, la mesa de turismo y paz en la región del UrabáDarién. En esta mesa se tuvo la oportunidad de discutir con actores locales, regionales y nacionales del turismo, dentro de los que estuvieron representantes del Viceministerio de Turismo, la Gobernación de Antioquia y del Chocó, las Alcaldías de Necoclí, Arboletes, Apartadó, Turbo y Acandí, así como miembros de la organización Guardagolfo y actores del turismo de la región (Naranjo, 2014). Allí se trataron aspectos como el tema de la formalización del sector, la prevención

5 El turismo de naturaleza es aquel cuya principal motivación es la observación de la naturaleza.

6 Las experiencias turísticas únicas son una estrategia de promoción establecida por el Ministerio de Comercio, Industria y Turismo, con la cual se busca que la oferta turística colombiana tenga un alto grado experiencial, de tal forma que no solamente el recurso o producto turístico sea el promocionado, sino que sea una experiencia que solamente se pueda vivir en Colombia. 
de crímenes ${ }^{7}$ en relación con el turismo, la oferta institucional de apoyo al desarrollo del sector y las necesidades que enfrenta la región en términos de infraestructura, conectividad y desarrollo de producto turístico.

Con el fin de formalizar y encaminar los esfuerzos adelantados dentro de la estrategia de "Turismo, paz y convivencia”, el Ministerio de Comercio, Industria y Turismo, a través de la Resolución 3159 de 2015, creó el Comité de Turismo, Paz y Convivencia, el cual tiene como objetivo:

Planear, dirigir, concertar y apoyar conjuntamente con las regiones la ejecución de las estrategias asociadas a la iniciativa de Turismo, Paz y Convivencia, que se lleven a cabo en el marco de las bases del Plan Nacional de Desarrollo 2014-2018, el Plan Sectorial de Turismo, “Turismo para la construcción de la paz” y el Plan Estratégico Sectorial 2015-2018, y en desarrollo de la “Declaración de Bogotá de Paz a través del Turismo".

Mediante este comité ${ }^{8}$ se busca establecer un mecanismo de diálogo directo y formal entre representantes del sector público, privado y la comunidad, con el fin de establecer los avances en el desarrollo del turismo en estas regiones piloto, analizar las dificultades y diseñar estrategias comunes en beneficio de los destinos. Si bien la existencia de este comité sirve como espacio de diálogo para el diagnóstico de las carencias y las necesidades de los destinos, se podría pensar en la creación de un órgano de composición mixta que permita una planeación y gestión conjunta en pro del desarrollo del turismo en estos territorios.

Ahora bien, dentro de las acciones que se han desarrollado en el marco de la estrategia "Turismo, paz y convivencia", antes o después de la conformación del comité, se pueden destacar la estrategia de promoción "Ruta caminera Necoclí-El Carlos", liderada por la Gobernación de Antioquia, a través de la Secretaría de Productividad, la cual busca estimular y conocer los sitios turísticos y atractivos naturales de la región del Urabá. Allí participaron periodistas, operadores turísticos, estudiantes locales y visitantes.

Estrategias como esta buscan dar a conocer sitios hasta el momento inexplorados pero que, debido a sus características naturales propias y a los desarrollos productivos que se han llevado a cabo, pueden tener un gran potencial para el turismo. Así las cosas, la apropiación por parte de los turistas de territorios en los que pudieron haber tenido presencia grupos armados ilegales, sumada a la generación de ingresos y a la inclusión social que el turismo

\footnotetext{
7 Aquí se hace referencia a crímenes como la explotación sexual comercial de niños, niñas y adolescentes asociada al turismo.

8 La Resolución 3159 de 2015 establece que el comité estará conformado por el viceministro de Turismo, el director de Análisis Sectorial y Promoción del Ministerio de Comercio, Industria y Turismo, un representante del Programa de Transformación Productiva, un representante de cada una de las entidades territoriales del orden departamental o municipal en las que se encuentren las regiones que integran la estrategia de turismo, paz y convivencia, y un representante de una organización de base empresarial o comunitaria de cada una de las regiones que integran la iniciativa de turismo, paz y convivencia, seleccionados por las mesas regionales de trabajo correspondientes (Ministerio de Comercio, Industria y Turismo, 2015).
} 
pueda generar en una región como el UrabáDarién, puede crear las condiciones para la construcción de paz.

Vistas las potencialidades del desarrollo alrededor del turismo en la región, bajo la premisa del desarrollo inclusivo, y con el apoyo de los gobiernos nacional y regional, organizaciones internacionales y la empresa privada, en el 2010 nació Guardagolfo, una asociación privada para el desarrollo alternativo de base comunitaria y de economía solidaria. Según información de la UNODC (2016), todo este proceso inició en el 2007 con la inclusión de 640 familias en estado de vulnerabilidad (desplazados, madres cabeza de familia, afrodescendientes, reinsertados e indígenas), que buscaban un desarrollo rural productivo, sostenible y bajo el margen de la legalidad.

De allí salieron 18 organizaciones de base orientadas a actividades como la pesca, el turismo de naturaleza y las artesanías, las cuales darían, posteriormente, origen a Guardagolfo.

Dentro de su propuesta de valor, Guardagolfo ofrece al turista en el Urabá-Darién cuatro centros ecoturísticos: El Carlos, Playa Caná, Posadas del Río e Iracas de Belén. Dentro de las actividades que les es posible realizar a los turistas se encuentran el avistamiento de aves y tortugas, senderismo y el clásico turismo de sol y playa. Cabe anotar en este punto que la misma asociación ofrece a los turistas los servicios de alojamiento, alimentación y guía turística (Ecogolfo, 2016).
Considerado como una forma de conocer la cultura del destino que se visita de una mejor manera, el turismo de artesanías también hace parte de este proyecto de desarrollo productivo en la región del Urabá-Darién. Así, las artesanías locales, a partir de tejido en palma de cańa flecha, tejido en calceta de plátano, tejido en palma de iraca, al igual que la talla de madera y bisutería, también hacen parte de la oferta que se le hace al turista (Ecogolfo, 2016).

La tabla 1 muestra los beneficios que trajo la iniciativa Guardagolfo en la región del Urabá-Darién y su comunidad en el periodo 2007-2012. Aquí se pueden evidenciar los impactos en términos de adecuación de espacios productivos, adquisición de maquinaria y equipo, o familias beneficiadas durante el periodo de referencia. Hay que tener en cuenta que actividades como el transporte, la producción agrícola o la misma pesca, de una manera u otra se vinculan en algún momento de la cadena de valor con el turismo (Yunis, 2011), sea mediante la venta de un bien o la prestación de un servicio. Debido a esto, se puede considerar que todos los impactos reportados en la tabla 1 se relacionan de forma directa o indirecta con el turismo.

En términos de comercialización, vale la pena resaltar la participación de la agencia Travel Tours Colombia del Urabá en la vi versión del Salón del Producto Turístico ${ }^{9}$ en Medellín, donde presentó su producto Visita

\footnotetext{
9 El Salón del Producto Turístico es una iniciativa para el desarrollo y fortalecimiento del turismo en Antioquia, liderada por la Subsecretaría de Turismo de la Alcaldía de Medellín, la Gobernación de Antioquia, la Cámara de Comercio de Medellín, entre otras entidades. Este salón está dirigido a empresarios del sector y busca que ellos
} 
TABLA 1. IMPACTOS DE LA INICIATIVA GUARDAGOLFO ENTRE EL 2007 Y EL 2012

\begin{tabular}{|c|c|}
\hline Descripción & Datos cuantitativos \\
\hline Centro de acopio para almacenamiento y comercialización de productos pesqueros & 8 \\
\hline Adquisición de botes de fibra con motores cuatro tiempos fuera de borda & 64 \\
\hline Familias beneficiarias por labores de pesca artesanal sostenible & 287 \\
\hline Organizaciones productivas de pescadores artesanales & 10 \\
\hline Centros de turismo de naturaleza & 4 \\
\hline $\begin{array}{l}\text { Familias beneficiadas en la prestación de servicios de alojamiento, recepción, alimentación, } \\
\text { guía e interpretación ambiental }\end{array}$ & 131 \\
\hline Familias vinculadas a la producción artesanal con materiales naturales de la región & 99 \\
\hline Centros artesanales para la elaboración de artesanías & 3 \\
\hline Familias vinculadas a la producción agrícola & 59 \\
\hline Colmenas en producción de miel y subproductos & 1500 \\
\hline Planta de transformación y envasado de productos apícolas & 1 \\
\hline $\begin{array}{l}\text { Hectáreas de plantaciones de caucho establecidas con clones de alto rendimiento como } \\
\text { actividad productiva de mediano y largo plazo, asociadas a cultivos de maíz, arroz, frijol, entre } \\
\text { otros, como alternativa en la generación de ingresos en la etapa improductiva }\end{array}$ & 322 \\
\hline Precooperativas de caucho & 2 \\
\hline Familias beneficiadas de actividades productivas relacionadas con el caucho & 70 \\
\hline
\end{tabular}

Fuente: Banco de Buenas Prácticas (s. f, pp. 3 y 4).

Urabá. Con él se hizo merecedor de uno de los premios que otorga este evento a las propuestas con mejor valor agregado y que aporten al portafolio de Antioquia, para atraer turismo receptivo ${ }^{10}$ de alto nivel, según lo reconoce la Cámara de Comercio de Medellín (2015). Aunque esta agencia de viajes es una empresa privada, demuestra el interés del sector privado en aprovechar la potencialidad turística que tiene la región del Urabá-Darién.
Por su parte, en términos de desarrollo de la competitividad del sector en la región, se debe rescatar la construcción de la agenda de competitividad turística del Urabá, hecha por la Cámara de Comercio del Urabá y la Corporación Turística Urabá-Darién, en el 2015, en la cual se priorizaron cinco proyectos relacionados con: producto de naturaleza, producto de cultura, proyecto de señalización

presenten, ante expertos nacionales e internacionales, su oferta de productos y servicios con un alto valor agregado, que puedan aportar a la oferta turística de Antioquia (Cámara de Comercio de Medellín, 2015).

10 Para definir el tipo de turismo en el que un sitio de interés recibe visitantes. 
turística, fortalecimiento empresarial y plan de marketing.

Estas iniciativas son la muestra de que se están generando procesos de apropiación o sentimiento de pertenencia local por parte de la comunidad, en cuanto a sus modelos de desarrollo y procesos necesarios, tal y como fue presentado en el capítulo anterior, para la construcción de escenarios de paz. En esta apropiación, el turismo ha jugado un papel fundamental, ya que mediante él se ha logrado una organización de la comunidad en torno a modelos de producción que redunden en beneficios para sus habitantes.

Sin embargo, son muchas más las acciones que se pueden desarrollar en el marco de la estrategia de "Turismo, paz y convivencia", si se quiere potenciar al turismo en la región del Urabá-Darién, como motor de desarrollo y medio para el establecimiento de escenarios de paz y convivencia.

En este sentido, hay que tener en cuenta que dentro del Comité de Turismo, Paz y Convivencia se han logrado identificar ciertas necesidades o intereses que la comunidad encuentra como vitales para lograr un desarrollo económico y social a través del turismo. Dentro de estas se podrían destacar el mejoramiento de la conectividad digital que permita ampliar los servicios financieros con los que cuentan los visitantes y que les faciliten los pagos; la capacitación en temas como el avistamiento de aves, fauna y flora; guía turística, inglés para el turismo, contabilidad y finanzas, manejo de redes sociales y tecnologías para el turismo; la vinculación de las familias y las iniciativas locales en la cadena y el producto turístico; o el fortalecimiento de las organizaciones comunitarias en temas como la formalización dentro del sector turismo (Comité Nacional de Turismo, Paz y Convivencia, 2015).

Identificadas estas necesidades, el Ministerio de Comercio, Industria y Turismo, dentro de sus competencias, está adelantando capacitaciones en la región de Urabá-Darién, en temas tales como la formalización turística y la sostenibilidad. Además, mediante una articulación con las entidades competentes en cada uno de los temas, se están coordinando agendas de trabajo con entidades tales como el Ministerio de las Tecnologías de la Información y las Comunicaciones o el Servicio Nacional de Aprendizaje (SENA), en las necesidades identificadas en la región del Urabá-Darién ya mencionadas. En este punto, y en aras de un trabajo que lleve a resultados reales para la población, se haría necesaria la creación de un plan integral de desarrollo turístico sostenible, con unos horizontes de tiempo fijos, unos indicadores claros de gestión y resultado y la asignación de un presupuesto.

Si bien el panorama parece alentador, no se deben dejar de lado los efectos adversos que puede traer el turismo, y que se traducen en nuevas formas de violencia, como pueden ser los robos o las tensiones entre los turistas y los locales. Se debe recordar que estos territorios han sufrido todos los rigores de la violencia armada en Colombia, lo que los podría hacer atractivos para practicar lo que la literatura ha llamado turismo oscuro, y que generaría una preocupación adicional en términos del manejo de la memoria histórica. 


\section{CONCLUSIONES}

La creciente llegada de visitantes a la región parece demostrar que el Urabá-Darién le ha apostado al turismo como un sector que le permitirá una mayor cohesión social entre sus habitantes y una generación de ingresos, mediante el desarrollo de actividades directamente relacionadas con la prestación de servicios turísticos o actividades como la pesca, las artesanías o la agricultura, que de manera directa o indirecta se relacionan con la cadena de valor del sector.

La disminución de la violencia directa en la región del Urabá-Darién, demostrada por el número decreciente de homicidios o hurtos, se ha traducido en la construcción de una paz negativa en la zona. Esto, si bien podría explicarse por la baja influencia que los grupos al margen de la ley tienen en la región, también podría verse desde la perspectiva de consolidación del control territorial que las fuerzas armadas ejercen en la actualidad.

El modelo de desarrollo turístico de base comunitaria y de economía solidaria que se está implementando en la región ha logrado un fortalecimiento de la cohesión social y de los imaginarios sociales, mediante un mayor relacionamiento entre pescadores, artesanos, productores agrícolas y prestadores de servicios turísticos, confirmando de esta manera la hipótesis planteada al inicio de la investigación. En este sentido, se podría concluir que el turismo en la región está ayudando a la construcción de una paz neutra y, en un futuro, a una paz positiva, ya que su misma dinámica favorece el mejor entendimiento de las necesidades y los intereses del otro.
En este sentido, se podría percibir que el turismo puede ser una actividad económica para el Urabá-Darién, en la cual pueden confluir excombatientes y víctimas, que permita el desarrollo de procesos productivos, la generación de ingresos, pero, más importante aún, el mejor entendimiento del otro y la reconstrucción del tejido social.

Teniendo en cuenta los efectos negativos que puede traer el turismo, y en busca de una sostenibilidad en los procesos, el modelo de desarrollo turístico en la región del UrabáDarién debería mantener su espíritu de base comunitaria e inclusiva, que tenga en cuenta también a la población que ha sido victimaria, pero que, en un escenario de posconflicto, retornará a la vida civil y necesitará integrarse de una manera efectiva a la sociedad.

Si este componente no se tiene en cuenta, y el desarrollo de procesos turísticos en la región no contempla la inclusión de todos los actores de la sociedad, se puede correr el riesgo de reactivar los niveles de violencia entre sus pobladores, como producto del no entendimiento de las necesidades y los intereses del otro.

Por otro lado, el mantenimiento de la seguridad seguirá siendo un prerrequisito para la realización del turismo en la región del Urabá-Darién, por lo cual, la influencia de organizaciones armadas al margen de la ley definitivamente afectará el desarrollo de procesos productivos en torno a este sector.

Finalmente, el turismo en la región del Urabá-Darién ha logrado un creciente grado de apropiación de la comunidad alrededor de modelos de desarrollo que se ven traducidos en beneficios para sus habitantes, como lo es 
la asociación Guardagolfo. Esta apropiación local, aunada a los esfuerzos de los gobiernos regional y nacional, mediante estrategias como el Salón del Producto Turístico o la estrategia "Turismo, paz y convivencia", resulta fundamental para la construcción y el mantenimiento de escenarios de paz.

\section{REFERENCIAS}

Aguilera, M. M., Bernal, C. y Quintero, P. (2006). Turismo y desarrollo en el Caribe colombiano. Cartagena de Indias: Banco de la República.

Alcaldía de Acandí-Chocó (2016). Información general. Equidad, transparencia y solución. Recuperado de http://www.acandi-choco.gov.co/informacion_general.shtml\#economia

Calderón, P. (2009). Teoría de conflictos de Johan Galtung. Revista Paz y Conflictos (2), 60-81.

Cámara de Comercio de Bogotá (2016). Sistema integrado de información. Recuperado de http:// rnt.rue.com.co

Cámara de Comercio de Medellín (2015). Salón de Producto Turistico: un espacio para el fortalecimiento de este sector en la ciudady la región. Recuperado de http://www.camaramedellin.com.co/site/Noticias/Salon-de-Producto-Turistico-un-espaciopara-el-for.aspx

Cantillo, J. L. (2015). Las teorías del origen del conflicto armado en Colombia. El Heraldo. Recuperado de http://www.elheraldo.co/politica/ las-teorias-del-origen-del-conflicto-armado-encolombia-184562

Comisión Histórica del Conflicto y sus Víctimas (2015). Contribución al entendimiento del conficto armado en Colombia. La Habana: Mesa de Conversaciones. Recuperado de https:// www.mesadeconversaciones.com.co/sites/default/files/Informe\%20Comisi_n\%20Hist_rica\%20del\%20Conflicto\%20y\%20sus\%20V_ ctimas.\%20La\%20Habana,\%20Febrero\%20 de\%202015.pdf

Comité Nacional de Turismo, Paz y Convivencia (2015). Acta 1. Documento de Trabajo Interno. Bogotá. Ecogolfo (2016). Home. Recuperado de http://www. ecogolfo.com.co/

Emprender Paz (s.f.). Banco de buenas prácticas. Recuperado de http://emprenderpaz.org/recursos/ banco-de-buenas-practicas

El Colombiano (2015). Urabá registra histórica baja de los homicidios. El Colombiano.

El Tiempo (2016). Así se moderniza la infraestructura de los aeropuertos chicos del país. El Tiempo. Recuperado de http://www.eltiempo.com/economia/ sectores/mejoras-en-aeropuertos-pequenos-decolombia/16496845

El Tiempo Economia y Negocios (2015). Empleo en turismo superó meta del cuatrienio 2011-2014: llegó a 235.000. El Tiempo. Recuperado de http://www.eltiempo.com/economia/sectores/ empleo-en-el-sector-turismo-crecio-175-porciento/15653638

Fondo Nacional de Turismo (Fontur) (2015). Detalle del proyecto. Recuperado de http://fontur.com. co/detalle-de-proyecto/25/25/0/2/15670

Galtung, J. (1990). Cutural Violence. Journal of Peace Research, 27 (3), 291-305.

Jiménez, F. (2009). Hacia un paradigma pacífico: la paz neutra. Convergencia. Revista de Ciencias, 16, 141-189.

Lacouture, M. C. (2016). Buenas noticias de Pascua para el turismo. Portafolio. Recuperado de http://www.portafolio.co/opinion/mariaclaudia-lacouture/turismo-tercera-industriaatrae-divisas-despues-petroleo-carbon-493297 
Migración Colombia (2016). Cifras de llegadas de viajeros extranjeros no residentes en Colombia. Bogotá: Migración Colombia.

Ministerio de Comercio, Industria y Turismo (2015). Resolución 3159. República de Colombia.

Ministerio de Comercio, Industria y Turismo (2016). Reporte de febrero del 2016. Recuperado de http://www.mincit.gov.co/publicaciones. php?id $=16590$

Ministerio de Comercio, Industria y Turismo y Viceministerio de Turismo y Departamento Nacional de Planeación (2014). Plan Sectoral de Turismo 2014-2018. Turismo para la costrucción de la paz. Bogotá: MinComercio.

Ministerio de Comerico, Industria y Turismo (2015). Reporte de diciembre del 2015. Recuperado de http://www.mincit.gov.co/publicaciones. php?id $=16590$

Ministerio de Defensa, Policía Nacional, Dirección de Investación Criminal e Interpol (s.f.). Obtenido de cifras, delitos y operatividad PONAL. Recuperado de http://oasportal.policia.gov.co/imagenes_ponal/dijin/observatorio/cicri/cifras.html

Moreno, É. y Ochoa F. (2011). Turismo sostenible, cadena de valor y participación comunitaria en Suesca (Cundinamarca), Colombia. Turismo y Sociedad, 12, 197-214.

Naranjo, N. (2014). Communitarian ecotourism in the colombian Darién and Urabá region: an opportunity for peace-building. En Wintersteiner, W. (ed.). International Handbook on Tourism and Peace (pp. 143-153). Klagenfurt: Drava.

Naranjo, N. (2014). Taller y mesa de trabajo de turismo, paz y conviviencia. Turismo Hoy.

Observatorio del Programa Presidencial de Derechos Humanos y Derecho Internacional Humanitario (2003). Panorama actual del Chocó. Colombia. Recuperado de http://historico.derechoshuma-
nos.gov.co/Observatorio/Publicaciones/documents/2010/Estu_Regionales/04_03_regiones/ choco.pdf

Observatorio del Programa Presidencial de Derechos Humanos y Derecho Internacional Humanitario (2006). Dinámica reciente de la confrontación armada en el Urabá Antioqueño. Recuperado de http://historico.derechoshumanos.gov.co/ Observatorio/Publicaciones/documents/2010/ Estu_Regionales/uraba.pdf

Oficina de las Naciones Unidas contra la Droga y el Delito (UNODC) (2012). Cultivos de Coca: estadisticas municipales. Censo del 31 de diciembre del 2011. Recuperado de https://www.unodc. org/documents/colombia/Documentostecnicos/ COCA_MUNICIPIOS_2011_internet.pdf

Organización de las Naciones Unidas (2015). Declaración de Medellin sobre turismo y transporte aéreo al servicio del desarrollo. Recuperado de http://cf.cdn.unwto.org/sites/all/files/pdf/unwto_icao_m_statement_sp.pdf

Organización Mundial de Turismo (омт) (2015). Panorama OMT del turismo internacional. Recuperado de http://www.e-unwto.org/doi/ pdf/10.18111/9789284416875

Organización Mundial del Turismo (омт) (1980). Conferecia Mundial de Turismo. Declaración de Manila sobre el turismo mundial. Recuperado de http://www.e-unwto.org/doi/pdf/10.18111/ unwtodeclarations.

Organización Mundial del Turismo (омт) (2015). Historia. Recuperado de http://www2.unwto. org/es/content/historia

Procolombia (2016). Chocó, Colombia: paisajes salvajes. Colombia es realismo mágico. Recuperado de http://www.colombia.travel/es/a-donde-ir/ pacifica/choco/actividades/capurgana 
Rožič, P. J. (2008). Stathis Kalyvas: The logic of violence in civil war. Perspectives, 16 (2).

Rettberg, A. (2013). La construcción de paz bajo la lupa: una revisión de la actividad y de la literatura académica internacional. Estudios Politicos (42), 13-36.

Revista Dinero (2016). Los más grandes desafíos para el turismo en Colombia. Publicaciones Semana. Recuperado de http://www.dinero.com/edicionimpresa/sectores/articulo/el-turismo-el-colombia-crecio-69-generando-11-billones/219407

Unidad para la Atención y la Reparación de las Víctimas (2015). DT Urabá-Darién: “reparamos a las victimas, aqui comienza la paz”. Bogotá: Gobierno Nacional.

UNODC (2016). Asociación Guardagolfo, un ejemplo para el pais. Recuperado de http://www.unodc.org/ colombia/es/news/guardagolfo.html
Verdad Abierta (2011). La madera, otro negocio de grupos armados ilegales. Recuperado de http:// www.verdadabierta.com/otros-negocioscriminales/3548-la-madera-otro-negocio-degrupos-armados-ilegales

Wintersteiner, W. y Wohlmuther, C. (2014). Peace sensitive tourism: How tourism can contribute to peace. En Wintersteiner, W. (ed.).International Handbook on Tourism and Peace (pp. 31-61). Klagenfurt: Drava.

Yunis, E. (2011). El turismo como generador de equidad social. El turismo como inductor del desarrollo, de la inclusión social y de la integración regional - Tourism as an Inducer of Development, Social Inclusion and Regional Integration. Fortaleza: UNWTO. 